\title{
Importance of the jejunal hormone motilin
}

\author{
N. D. CHRISTOFIDES \\ From the Department of Medicine, Royal Postgraduate Medical School, Hammersmith Hospital, \\ Du Cane Road, London W12 OHS
}

\section{History}

In 1935, Shay and Gershon-Cohen showed that luminal perfusion of the duodenum of human subjects with sodium bicarbonate solution produced a rapid emptying of a barium sulphate meal from the stomach. More recently it was shown by Brown et al. (1966) that, in the dog, the instillation of alkaline solutions into the duodenum also increased motor activity in denervated, transplanted gastric pouches. A similar response was also observed after the instillation of pig pancreatic juice into the denervated pouch. The authors suggested that the alkaline solutions either prevented the release of an inhibitory hormone or released a stimulatory agent for motor activity. Brown et al. in 1971, using as starting material a peptide fraction produced as a byproduct during the purification of secretin on carboxymethyl cellulose, reported on the preliminary stages of purification of the motor-stimulating material. The purification showed that it was a polypeptide which was given the name motilin.

\section{Structure}

Motilin is a single chain polypeptide containing 22 amino-acid residues (Brown et al., 1973), Phe-ValPro-Ile-Phe-Thr-Tyr-Gly-Glu-Leu-Gln - ArgMet-Gln-Glu-Lys-Glu-Arg-Asn-Lys-Gly-Gln. It has no obvious structural relationship to any other biologically active polypeptide. The first synthesis of a motilin-like molecule was carried out with norleucine (13-Nle-motilin) in place of methionine (Wünsch et al., 1973), thus avoiding the problem of accidental oxidation of the sulphur-containing amino-acid. The $\mathbf{N}$ terminal region appeared to be important for biological activity. Removal of the terminal 5 amino-acids from the $\mathrm{N}$ terminus destroys $98 \%$ of the biological activity. Removal of the corresponding $\mathrm{C}$ terminal amino-acids has no such effect. Thus, the $\mathbf{N}$ terminus is essential for biological activity, unlike gastrin and cholecystokinin.

The synthetic analogue, 13-Nle-motilin, has biological and immunological activities identical with those of the natural porcine motilin (Strunz et al., 1976).

\section{Radioimmunoassay}

The only technique sufficiently sensitive to measure the minute amounts of motilin in plasma is radioimmunoassay. The first assay for measuring plasma motilin was described by Dryburgh and Brown (1975). Since then several others have been reported (Bloom et al., 1976; Chey et al., 1978; Track et al., 1978). The $\mathrm{I}^{125}$ motilin label prepared by conventional oxidation techniques was found to be stable for many months when kept at $-20^{\circ} \mathrm{C}$, and immunoreactive motilin appears to be stable for at least three hours in plasma or whole blood, and only about $20 \%$ of it is lost after 24 hours.

Antibodies have proved easy to raise in rabbits using porcine motilin conjugated by carbodiimide to bovine serum albumin. The antibody (Ml) used in our routine plasma motilin estimation at a final dilution of $1 / 320000$ showed no cross-reaction with other gut hormones and did not significantly react with up to $100 \mathrm{pmol} /$ tube of synthetic motilin fragments 1 to 6,12 to 22 , and 7 to 22 . Another antiserum (GP71) from Professor J. C. Brown, however, did show significant cross-reaction with the C terminal fragments 12 to 22 and 7 to 22 . Gel chromatography of duodenal extracts and plasma samples using our antiserum Ml showed motilin immunoreactivity eluting in two separate peaks, the slower of which eluted in the same volume as the natural porcine motilin. The other peak apparently eluted much earlier from Sephadex G100 suggesting a greater molecular weight.

When the column fractions were assayed with the GP71 antiserum, the earlier peak was only partially detected whereas the later peak was of a similar magnitude. Thus, either the faster motilin peak detected with antiserum M1 has a part of its immunoreactivity absent or occluded, or it is a different hormone entirely which has partial cross-reactivity with motilin.

The rise in plasma levels of both motilins is 
identical after applying different stimuli (somatostatin, fat, a meal, or gastric distension). This suggests that the 'big' faster eluting motilin might be related to the classical moiety detected by both antisera. The nature and biological significance of the big form is under investigation.

\section{Localisation}

The distribution of motilin in the human alimentary tract, assessed by radioimmunoassay, was described by Bloom et al. (1976). High concentrations were found in the human duodenum and jejunum, and small amounts in the gastric antrum. Immunohistochemical studies have shown it to be localised to the granules of the enterochromaffin cell (Polak et al., 1975).

\section{Actions of motilin}

Motilin has powerful effects on the smooth muscle of the gastric antrum, duodenum, and colon. Smooth muscle in other organs (uterus, gall bladder, other parts of the intestine) does not respond to it. Its effect is about 50 times greater (in molar terms) than that of acetylcholine (Strunz et al., 1975), and it is not inhibited by atropine (anticholinergic), hexamethonium (ganglion blocker), tetrodoxin (axonal blocker), or pheniramine (antihistaminic) (Strunz et al., 1975). A direct effect on the muscle cell has been suggested.

The contractile response to motilin was abolished by the $\mathrm{Ca}^{2+}$ antagonistic compound verapamil, thus suggesting that $\mathrm{Ca}^{2+}$ ions are involved in the action of motilin. As cyclic GMP is known to produce a rapid release of $\mathrm{Ca}^{2+}$ from microsomal fractions (Andersson et al., 1976), it is possible that cyclic GMP may also be involved in motilin-induced gastrointestinal smooth muscle contractions. It was reported recently (Schubert et al., 1975) that motilininduced contraction of the duodenal muscle is associated with a concomitant increase in intracellular cyclic GMP.

MOTILITY OF THE STOMACH AND DUODENUM In 1975 Ruppin et al. reported that infusion of graded doses of 13-Nle motilin in three subjects resulted in a dose-dependent delay in the gastric emptying of a liquid test meal. The doses of motilin used were $0.6,1 \cdot 2$, and $2.4 \mathrm{pmol} / \mathrm{kg} / \mathrm{min}$. The lowest dose caused a $43 \%$ delay in the gastric emptying. Unfortunately, plasma motilin levels were not reported.

Recently Christofides and co-workers (1979) showed that infusion of natural porcine motilin in five subjects resulted in a significant acceleration of gastric emptying after a solid meal (Fig. 1). The

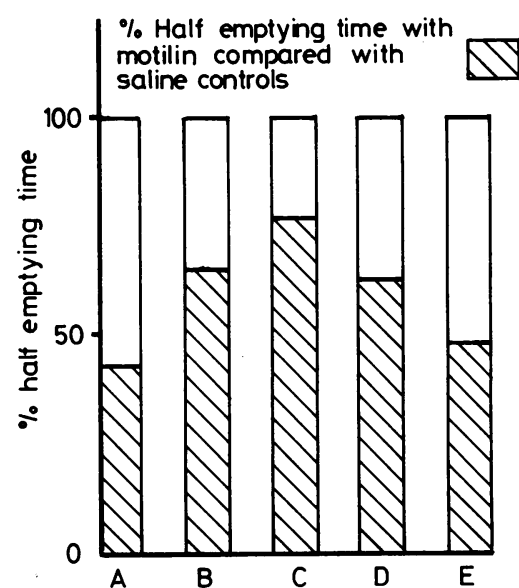

Fig. 1 Gastric half emptying time stimulated by motilin (shaded areas) in 5 subjects, expressed as a percentage of the corresponding saline control.

dose of motilin was $0.34 \mathrm{pmol} / \mathrm{kg} / \mathrm{min}$ and this $\overrightarrow{0}$ produced a rise in plasma motilin of $58 \mathrm{pmol} / 1$ whish is within the physiological range of motilin fluctu tions. These apparently conflicting findings are negt easily reconciled. It is possible that the discrepaney might be because of the use of different methods, for example, in the original study the subjects were not $\stackrel{\circ}{\mathcal{O}}$ studied blind and anxiety may have played a role. On the other hand it may be that motilin differentially controls the emptying of solids and liquids. Infusion of motilin in dogs (Debas et al., 1977) resulted in a significant enhancement of the emptying rate of a liquid meal but had no apparent effect on the emptying rate of solids. More studies are clearly음 needed to establish the exact role of motilin in the control of gastric emptying.

In 1976, Ruppin and colleagues reported that $133^{3}$ Nle motilin accelerated the intestinal transit time of $\mathrm{O}$ a barium sulphate meal when infused at a rate of $2 \cdot 5 \mathrm{pmol} / \mathrm{kg} / \mathrm{min}$.

ELECTRICAL AND MECHANICAL ACTIVITY According to the findings of Code and Marlett (1975), $N$ in the fasting state a regular pattern of migrating myoelectrical spike activity arises in the stomach or duodenum and then migrates in a caudal directiono down the small intestine. After the cycle reaches the $\frac{\bar{\Phi}}{\Phi}$ distal ileum another cycle begins, the whole cycle? taking about 90 minutes. In the dog, and more recently in man (Itoh et al., 1975; Vantrappen et al.,, $\overrightarrow{+}$ 1978), it has been shown that infusion of motilin results in a gastrointestinal motor response which $\vec{\Phi}_{\varrho}$ resembles the naturally occurring interdigestiveত migrating myoelectric complex. Vantrappen et al. 
(1978) also showed that there is a relation between the onset of a new front and rising of the motilin levels. Fasting motilin levels before the onset of a front were significantly higher than the levels during a $30 \mathrm{~min}$ period after the front.

\section{OTHER ACTIONS}

Other actions of motilin in man include the stimulation of pepsin secretion (Ruppin et al., 1975), inhibition of gastric mucosal protein synthesis (Mitznegg et al., 1976b), increased postprandial release of insulin (Christofides et al., 1979), and increase in tone of the lower oesophageal sphincter (Lux et al., 1976). It is not yet clear, however, how many of these effects can be considered as physiological. Reports of experiments should always include not only the rate of infusion but also the plasma motilin levels before, during, and after the infusion.

\section{PHARMACOKINETICS}

During the infusion of synthetic 13-Nle-motilin at doses of 0.6 and $2.4 \mathrm{pmol} / \mathrm{kg} / \mathrm{min}$ for $40 \mathrm{~min}$ in man, plasma motilin rose to a plateau at 124 and 360 pmol/1, respectively (Mitznegg et al., 1977), and fell rapidly afterwards with first order kinetics and a half-life of $4.4 \mathrm{~min}$. The calculated metabolic clearance rate and apparent distribution space were $7.8 \mathrm{ml} / \mathrm{kg} / \mathrm{min}$ and $49.4 \mathrm{ml} / \mathrm{kg}$, respectively.

The half life of endogenous motilin was determined in man by following the changes in plasma concentration after the administration of somatostatin, and was found to be $4.6 \mathrm{~min}$ (Mitznegg et al., 1977). The infusion of natural porcine motilin at doses of 0.34 and $0.68 \mathrm{pmol} / \mathrm{kg} / \mathrm{min}$ resulted in plasma motilin increments of 58 and $102 \mathrm{pmol} / 1$ (Christofides et al., 1979). The half life was calculated to be $4.5 \mathrm{~min}$, the metabolic clearance rate was $6.7 \mathrm{ml} / \mathrm{kg} / \mathrm{min}$, and the apparent distribution space was $44 \mathrm{ml} / \mathrm{kg}$. Thus, the pharmacokinetics in man of natural porcine motilin, 13-Nle-motilin, and endogenous human motilin are very similar.

\section{Release of motilin}

It is obviously important when unravelling the physiological role of a hormone not only to discover what it does at a given blood concentration but also what stimuli are likely to result in such a rise of the hormone. It was thus essential to determine the mechanisms and the magnitude of the motilin release.

\section{EFFECT OF INTRADUODENAL PH}

It was reported by Mitznegg et al. (1976a) that in man, contrary to the findings in dogs, the instillation of $50 \mathrm{ml} 0 \cdot 1 \mathrm{M} \mathrm{HCl}$ into the duodenum caused the plasma motilin levels to rise by $90 \%$ within $4 \mathrm{~min}$. This amount of acid, however, can hardly be considered physiological, and recently we found that smaller amounts of endogenous acid secreted in response to pentagastrin did not increase plasma motilin (unpublished observations). A lack of correlation between plasma motilin and duodenal $\mathrm{pH}$ after a meal was found by Greenberg $e t$ al. (in preparation). It would thus appear that duodenal acidity is not an important physiological mechanism controlling the release of motilin in man. The instillation of $50 \mathrm{ml} 0.3 \mathrm{M}$ tris buffer, $\mathrm{pH} 10 \cdot 3$, into the duodenum in man resulted in a small fall of plasma motilin (Mitznegg et al., 1976a). This contrasts with the dog in which a significant release of motilin was observed after intraduodenal administration of alkali (Dryburgh and Brown, 1975). These findings suggest that considerable differences may exist between species.

\section{BASAL LEVELS}

The basal plasma motilin concentrations in 100 healthy subjects at 0900 to $1000 \mathrm{~h}$, after an overnight fast, are shown in Fig. 2. The distribution is skewed with levels ranging from 4 to $350 \mathrm{pmol} / \mathrm{l}$; the median was $60 \mathrm{pmol} / \mathrm{l}$ and the mean was $82 \mathrm{pmol} / \mathrm{l}$. Of all the subjects studied, $70 \%$ had fasting levels below $100 \mathrm{pmol} / \mathrm{l}$. There was no apparent correlation with age.

Preliminary data suggest that there is a marked diurnal rhythm in plasma motilin. Levels are much higher in the morning than later in the day, a point of great importance when interpreting plasma levels. The physiological significance of this diurnal rhythm is not yet clear, though it is noteworthy that cortisol has a similar pattern of release, and both motilin and cortisol levels in the plasma increase with strenuous exercise (unpublished observations). Further work on the possible role of motilin as a stress hormone, and the importance of the diurnal rhythm is clearly required.

\section{POSTPRANDIAL RELEASE}

It was suggested by Grossman et al. (1974) that for a gastrointestinal peptide to be assigned hormonal status it should be released by a meal. The effect of a normal breakfast of orange juice, two boiled eggs, buttered toast, and marmalade (66 $\mathrm{g}$ carbohydrate, $18 \mathrm{~g}$ protein, $22 \mathrm{~g}$ fat, and 530 calories) was therefore studied in a group of 28 normal subjects. Fifteen minutes after ingestion of the meal the plasma motilin had increased by 4 to $52 \mathrm{pmol} / \mathrm{l}$ (median, 22 $\mathrm{pmol} / \mathrm{l})$. The rise was short lived with plasma levels returning to basal by $60 \mathrm{~min}$ (Christofides et al., 1978b) (Fig. 3). 

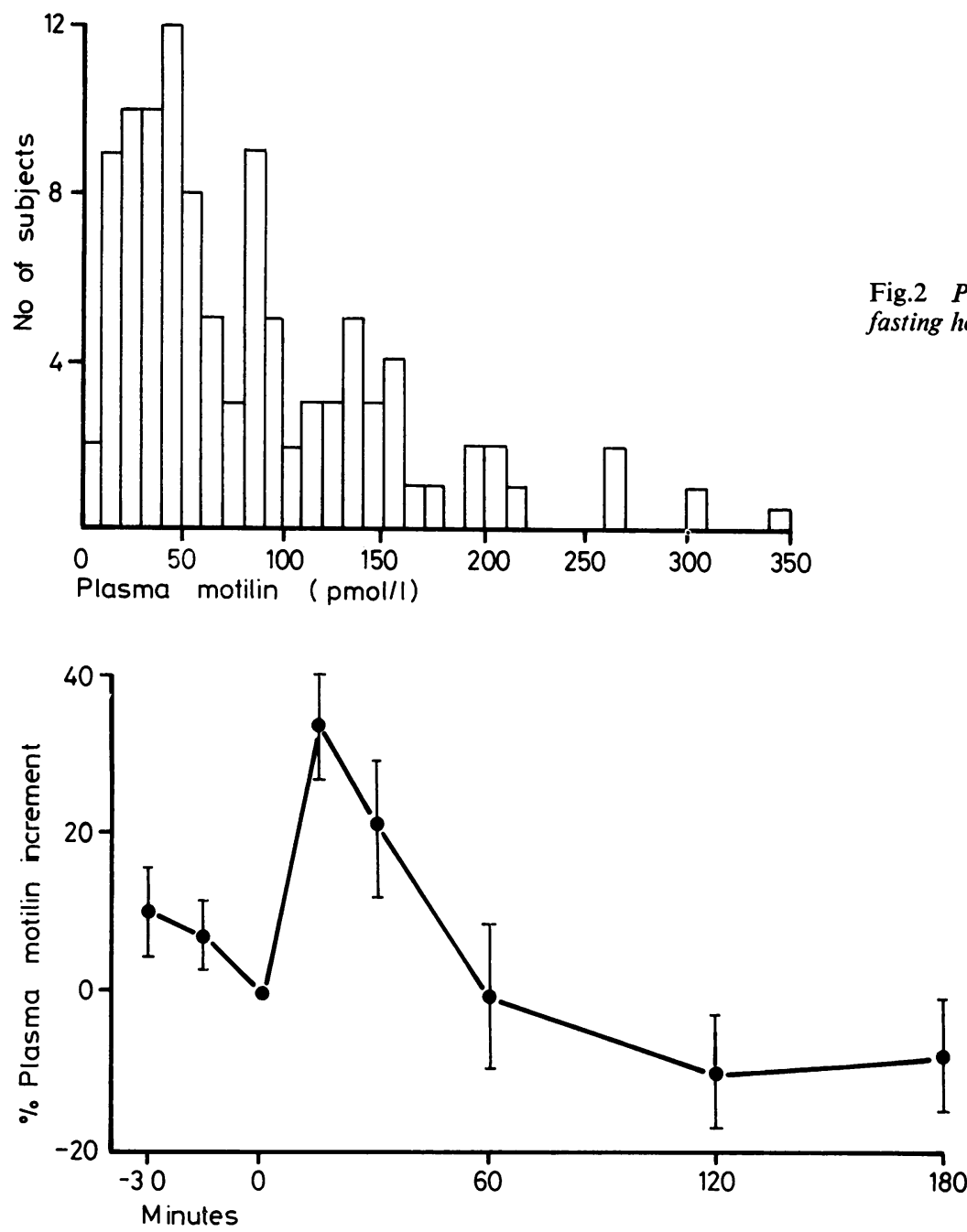

Fig.2 Plasma motilin levels in 100 fasting healthy subjects.
Fig. 3 Percentage plasma motilin increment in 28 subjects after a test meal.
To determine which of the meal components was responsible for this release, fat, glucose, and protein were administered separately. The ingestion of 120 $\mathrm{ml}$ double cream ( 515 calories, fat) made up to 500 $\mathrm{ml}$ with water caused plasma motilin levels to rise by $40 \mathrm{pmol} / 1$ (range 19 to $60 \mathrm{pmol} / \mathrm{l}$ ). In contrast the ingestion of $50 \mathrm{~g}$ glucose, made up to $250 \mathrm{ml}$ of water, resulted in a fall of plasma motilin of 35 pmol/l (3 to $320 \mathrm{pmol} / \mathrm{l}$ ) (Fig. 4). The ingestion of protein $(680 \mathrm{~g}$ steamed cod, total volume $500 \mathrm{ml})$ was followed by a small but statistically insignificant rise, but intravenous infusion of a protein hydrolysate resulted in a significant fall in plasma motilin. In contrast intravenous fat and glucose evoked responses identical to those after oral adminitration (Christofides et al., 1978b).
The different responses of motilin after oral and $\stackrel{ }{2}$ intravenous protein might possibly be the result of distension of the stomach. To test this hypothesis plasma motilin levels were measured after the $\mathcal{N}$ ingestion of $7.5 \mathrm{ml}$ water $/ \mathrm{kg}$ (about $500 \mathrm{ml}$ ) and N $15 \mathrm{ml} / \mathrm{kg}$, respectively, by healthy subjects (Christo- N fides et al., 1978c). The former was followed by a rise $\sigma$ of plasma motilin from a basal level of $68 \mathrm{pmol} / \mathrm{l}$ (range 15 to 82 ) to a peak of $107 \mathrm{pmol} / 1$ (range 40 to 220 ). Ingestion of $15 \mathrm{ml} / \mathrm{kg}$ water caused a rise $\stackrel{\Phi}{\oplus}$ from 40 (22 to 97$)$ to a peak of $103 \mathrm{pmol} / 1$ (43 to 184$)$. The response was unaffected by the previous administration of atropine.

These data suggest that the rise of motilin after $\frac{}{\mathbb{D}}$ a meal involves complex mechanisms. It is clear that $\frac{2}{\sigma}$ food components have an effect, either stimulating 


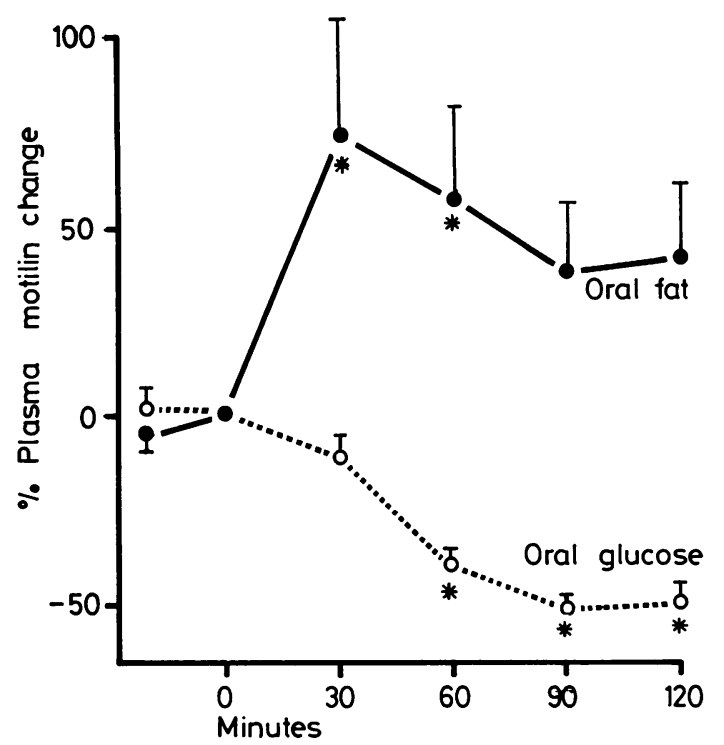

Fig. 4 Percentage plasma motilin change after ingestion of $120 \mathrm{ml}$ double cream (solid circles) or $50 \mathrm{~g}$ glucose (open circles).

or suppressing the release of motilin. A more profound effect was seen after the water load. The two doses given appear to release motilin to the same extent. This suggests an all or none effect of some change such as gastric distension or lowering of osmolality in the upper small intestine. The exact mechanism, however, is not understood though the cholinergic nervous system appears not to be involved. The role of the adrenergic system is under investigation.

The magnitude of the change in motilin levels after different stimuli varies in different subjects. Recently (Christofides et al., 1978b) a highly significant correlation was found between the basal levels and the extent of the rise or fall of plasma motilin, subjects with high basal levels showing a bigger rise than those with low basal levels. The response of different subjects may be compared by expressing the change as a percentage of the basal level.

\section{Pathology}

The above data suggest that motilin might have a role in the control of gastrointestinal motility, and might be implicated in the aetiology of various pathological states with motility disorders.

\section{DUMPING SYNDROME AND DUODENAL}

ULCERATION

Three groups of patients were studied after the ingestion of $75 \mathrm{~g}$ oral glucose (in $150 \mathrm{ml}$ of water). These included 19 postoperative patients with dumping symptoms, 20 matched patients after surgery for duodenal ulceration without dumping, and 20 preoperative duodenal ulcer patients. The fasting levels of motilin in the three groups were not significantly different. The increase in plasma motilin $\mathbf{3 0}$ min after the glucose in the patients with dumping symptoms was somewhat larger than in the other two groups $(39 \pm 20 \mathrm{pmol} / 1,5 \pm 5 \mathrm{pmol} / \mathrm{l}$, $18 \pm 7 \mathrm{pmol} / \mathrm{l}$, respectively), but the difference was not statistically significant. It appears, therefore, that motilin does not have an important role in the aetiology of the dumping syndrome in spite of the considerable changes in motility which are shown to occur.

Recently the effect of insulin-induced hypoglycaemia and a meal in controls and patients with active duodenal ulceration was reported (Christofides and Bloom, 1978). With insulin hypoglycaemia, motilin levels fell sharply in both the controls and in the patients with duodenal ulcer. An identical but more prolonged inhibition was also observed after truncal vagotomy. The magnitude of the motilin rise after ingestion of the meal was identical in the duodenal ulcer and control groups. These data thus suggest that motilin levels are not 'abnormal' in duodenal ulceration.

\section{DIARR HOEA}

In order to determine whether motilin might play a role in the abnormal motility associated with diarrhoeal states, fasting and postprandial motilin levels were measured in several groups of patients with diarrhoea or steatorrhoea (Bloom et al., 1978). It was shown that plasma motilin levels were significantly higher than normal in the following groups: (1) Crohn's disease; (2) ulcerative colitis; (3) acute tropical sprue (see paper by Dr Besterman, page 76);

(4) acute infective diarrhoea; (5) pancreatic disease;

(6) small intestinal resection.

In contrast, motilin levels in patients with constipation were not significantly different from the controls.

\section{Conclusion}

Since the discovery of motilin some progress has been made in elucidating its actions. The most profound effect of motilin appears to be the stimulation of gastrointestinal motility and gastric emptying. These might well be proved to be important physiologically. The finding that motilin levels are abnormal in some diseases associated with diarrhoea indicates the need for much further research. 
I would like to thank Dr S. R. Bloom and my colleagues at the Royal Postgraduate Medical School, London for their help and encouragement during these studies and Miss Alicia Barker for typing the manuscript. I am indebted to Professor Yanaihara, Shizuoka, Japan and Professor J. C. Brown, Vancouver, Canada for the provision of peptides and antibodies. This work was made possible by grants from the Wellcome Trust and Medical Research Council.

\section{References}

Andersson, R. G. G., Djärv, L., Nilsson, K., and Wikberg, J. (1976). The role of calcium and cyclic nucleotides in the regulation of tension in smooth muscles of the gastrointestinal tract. In StimulusSecretion Coupling in the Gastrointestinal Tract, pp. 1-13, ed R. M. Case and H. Goebell. MTP, Lancaster.

Bloom, S. R., Christofides, N. D., and Besterman, H. S. (1978). Raised motilin in diarrhoea (Abst.). Gut, 19, A959.

Bloom, S. R., Mitznegg, P., and Bryant, M. G. (1976). Measurement of human plasma motilin. Scandinavian Journal of Gastroenterology, 11, Suppl. 39, 47-52.

Brown, J. C., Cook, M. A., and Dryburgh, J. R. (1973). Motilin, a gastric motor activity stimulating polypeptide: the complete amino acid sequence. Canadian Journal of Biochemistry, 51, 533-537.

Brown, J. C., Johnson, L. P., and Magee, D. F. (1966). Effect of duodenal alkalinization on gastric motility. Gastroenterology, 50, 333-339.

Brown, J. C., Mutt, V., and Dryburgh, J. R. (1971). The further purification of motilin, a gastric motor activity stimulating polypeptide from the mucosa of the small intestine of hogs. Canadian Journal of Physiology and Pharmacology, 49, 399-405.

Chey, W. Y., Lee, K. Y., and Tai, H. H. (1978). Endogenous plasma motilin concentration and interdigestive myoelectric activity of the canine duodenum. In Gut Hormones, pp. 355-358, ed S. R. Bloom. Churchill Livingstone, Edinburgh.

Christofides, N. D., and Bloom, S. R. (1978). Plasma motilin levels in duodenal ulcer and effect of a truncal vagotomy and hypoglycaemia. Experientia, 34, 804 811.

Christofides, N. D., Bloom, S. R., and Besterman, H. S. (1978a). Physiology of motilin (2). In Gut Hormones, pp. 343-350, ed S. R. Bloom. Churchill Livingstone. Edinburgh.

Christofides, N. D., Bloom, S. R., Besterman, H. S., Adrian, T. E., and Ghatei, M. A. (1978b). Release of motilin by oral and intravenous nutrients in man. Gut, 20, 2, 102-106.

Christofides, N. D., Modlin, I. M., Fitzpatrick, M. L., and Bloom, S. R. (1979). Effect of motilin on the rate of gastric emptying and gut hormone release during breakfast. Gastroenterology, 76, 903-907.
Christofides, N. D., Modlin, I. M., Sarson, D. L., Albuquerque, R. H., Ghatei, M. A., Adrian, T. E., and Bloom, S. R. (1978c). The release of gastrin, PP, VIP and motilin after an oral water load and atropine in man (Abst.). Clinical Science and Molecular Medicine, 54, 12P-13P.

Code, C. F., and Marlett, J. A. (1975). The interdigestive myo-electric complex of the stomach and small bowel of dogs. Journal of Physiology, 246, 289-309.

Debas, H. T., Yamagishi, T., and Dryburgh, J. R. (1977). Motilin enhances gastric emptying of liquids in dogs. Gastroenterology, 73, 777-780.

Dryburgh, J. R., and Brown, J. C. (1975). Radioimmunoassay for motilin. Gastroenterology, 68, 1169-1176.

Grossman, M. I. et al. (1974). Candidate hormones of the gut. Gastroenterology, 67, 730-755.

Itoh, Z., Aizawa, I., Takeuchi, S. and Couch, E. F. (1975). Hunger contraction and motilin. In Proceedings of the 5th International Symposium on Gastrointestinal Motility, Leuven, Belgium, ed G. Vantrappen. Typoff Press, Herenthals.

Lux, G., Rösch, W., Domschke, S., Domsckhe, W., Wünsch, E., Jaeger, E., and Demling, L. (1976). Intravenous 13-Nle-motilin increases the human lower esophageal sphincter pressure. Scandinavian Journal of Gastroenterology, 11, Suppl. 39, 75-79.

Mitznegg, P., Bloom, S. R., Domschke, W., Domschke S., Wünsch, E. and Demling, L. (1976a). Release of motilin after duodenal acidification. Lancet, 1, 888889.

Mitznegg, P., Bloom, S. R., Domschke, W., Domschke, $\stackrel{\unrhd}{\varrho}$ S., Wünsch, E., and Demling, L. (1977). Pharma- $\overrightarrow{\vec{B}}$ cokinetics of motilin in man. Gastroenterology, 72, $\frac{0}{3}$ 413-416.

Mitznegg, P., Domschke, W., Domschke, S., Belohlavek, D., Sprügel, W., Strunz, U., Wünsch, E., Jaeger, E., and Demling, L. (1976b). Effects of in vivo admini-용 stration of pentagastrin, secretin and 13-Nle-motilin $:$ on the in vitro incorporation of 14 C-leucine into 3 . protein of human gastric mucosa. Scandinavian Journal of Gastroenterology, 11, 657-660.

Polak, J. M., Pearse, A. G. E., and Heath, C. M. (1975). Complete identification of endocrine cells in the gastro- $J$ intestinal tract using semithin-thin sections to identify $D$ motilin cells in human and animal intestine. Gut, 16, 225-229.

Ruppin, H., Domschke, S., Domschke, W., Wünsch, E., Jaeger, E., and Demling, L. (1975). Effects of 13-Nle-: N motilin in man-inhibition of gastric evacuation and $N$ stimulation of pepsin secretion. Scandinavian Journal of Gastroenterology, 10, 199-202.

Ruppin, H., Sturm, G., Westhoff, D., Domschke, S., Domschke, W., Wünsch, E., and Demling, L. (1976). Effect of 13-Nle-motilin on small intestinal transit time in healthy subjects. Scandinavian Journal of Gastroenterology, 11, Suppl. 39, 85-88

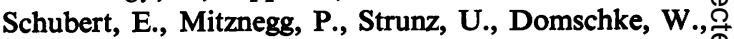
Domschke, S., Wünsch, E., Jaeger, E., Demling, L., $\stackrel{\mathbb{Q}}{2}$ and Heim, F. (1975). Influence of the hormone analogue 13-NLE-motilin and of 1-methyl-3-isobutyl-xanthine 
on tone and cyclic $3^{\prime}, 5^{\prime}$-AMP content of antral and duodenal muscles in the rabbit. Life Sciences, 16, 263-272.

Shay, H., and Gershon-Cohen, J. (1935). Experimental studies in gastric physiology in man: the mechanism of gastric evacuation after partial gastrectomy as demonstrated roentgenologically. American Journal of Digestive Diseases, 2, 608-613.

Strunz, U., Domschke, W., Domschke, S., Mitznegg, P., Wünsch, E., Jaeger, E., and Demling, L. (1976). Gastroduodenal motor response to natural motilin and synthetic position 13-substituted motilin analogues: a comparative in vitro study. Scandinavian Journal of Gastroenterology, 11, 199-203.

Strunz, U., Domschke, W., Mitznegg, P., Domschke, S., Schubert, E., Wünsch, E., Jaeger, E., and Demling, L. (1975). Analysis of the motor effects of 13-norleucine motilin on the rabbit, guinea pig, rat and human alimentary tract in vitro. Gastroenterology, 68, 14851491.

Track, N. S., Collins, S., Lewis, T., and Daniel, E. E. (1978). Motilin release and upper gastrointestinal motility in man. In Gut Hormones, pp. 351-354, ed S. R. Bloom. Churchill Livingstone, Edinburgh.

Vantrappen, G., Janssens, J., Peeters, T., Bloom, S. R., Christofides, N. D., and Hellemans, J. (1978). Intraduodenal $\mathrm{pH}$, motilin and interdigestive migrating motor complex in man. Scandinavian Journal of Gastroenterology, 13, Suppl. 49, 190.

Wünsch, E., Brown, J. C., Deimer, K. H., Drees, F., Jaeger, E., Musiol, J., Scharf, R., Stocker, H., Thamm, P., and Wendlberger, G. (1973). Zur Synthese von Norleucin-13-Motilin (vorläufige Mitteilung). Zeitschrift für Naturforschung, C, 28, 235-240. 